\title{
ВЫБОРЫ В ЕВРОПАРЛАМЕНТ 26 МАЯ 2019 г.: ОСОБЕННОСТИ ИЗБИРАТЕЛЬНОЙ КАМПАНИИ В ГЕРМАНИИ
}

Аннотация. Статья посвящена анализу подготовки немецких политических партий к выборам в Европейский парламент 2019 г. Для этого автор выделяет основные закономерности электорального поведения, изучает предвыборные программы и стратегии партий, представленных в бундестаге. Это позволяет сформулировать прогноз итогов выборов в Германии и то, как они повлияют на общий расклад сил в Европарламенте (ЕП). Особое внимание уделяется анализу позиций правительственных и оппозиционных партий по отношению к России, а так же перспективам немеиких политиков занять ключевые посты в Брюсселе после выборов.

Ключевые слова: партийно-политическая система Германии, правительственные партии, оппозиция, Европарламент, евроскептицизм, протестное голосование, электоральные предпочтения, «Альтернатива для Германии», российско-германские отнотения.

Выборы в Европарламент в ФРГ с начала их проведения в 1979 г. подчиняются собственной логике и следуют особым законам. Политологи отмечают их «второстепенное значение» для граждан и общественности ${ }^{1}$. В шкале приоритетов немецких избирателей они, как правило, находятся на четвёртом месте после выборов в бундестаг, ландтаги и органы местного самоуправления. Решения национальных парламентов оказывают, по мнению немцев, большее влияние на их жизнь, чем те, которые исходят из Брюсселя.

Таблица 1

Важность парламентов, по мнению немецких избирателей (\%)

\begin{tabular}{|l|c|c|c|c|c|c|c|}
\hline $\begin{array}{c}\text { Важность парламентских решений } \\
\text { (очень важны/важны) }\end{array}$ & Всего & $\begin{array}{c}\text { ХДС } \\
\text { /ХСС }\end{array}$ & СДПГ & $\begin{array}{c}\text { «Союз 90/ } \\
\text { Зелёные» }\end{array}$ & 《евая» & АдГ & Абсентеисты \\
\hline решения в бундестаге & 80 & 88 & 88 & 88 & 87 & 84 & 67 \\
\hline решения в Европарламенте & 59 & 61 & 66 & 72 & 63 & 66 & 46 \\
\hline решения в ландтагах & 79 & 87 & 86 & 84 & 85 & 76 & 68 \\
\hline решения в муниципальных/городских советах & 76 & 83 & 84 & 79 & 78 & 66 & 65 \\
\hline
\end{tabular}

Примечание: в таблице не учитываются данные опроса сторонников СвДП, т.к. они оказались незначительными.

Источник: Forum Empirische Sozialforschung. Wählen, wählen, immer wieder wählen. Die Bundestagwahl und Europawahl im Vergleich. Viola Neu, Sabine Pokorny, 2014, Konrad-Adenauer-Stiftung. EV Sankt Augustin/Berlin, S.31.

Невысокая оценка роли Европарламента (59\%) оказывает существенное влияние на ход и итоги выборов в ЕП, определяет поведение электората и формирует свои особые законы. Как правило, активность избирателей - ниже, готовность экспериментировать - выше. Это приводит к успеху малых партий, которым нередко удаётся добиться вторых по значимости результатов. Отмена Конституционным судом ФРГ существовавшего до 2014 г. 5\%-ного

(C) Тимошенкова Екатерина Петровна - кандидат исторических наук, ведущий научный сотрудник Центра германских исследований Отдела страновых исследований ИЕ РАН. Адрес: 125009, Россия, Москва, ул. Моховая, д. 11, стр. 3.E-mail: katerinatim@mail.ru.

DOI: http://dx.doi.org/10.15211/vestnikieran220195258

${ }^{1}$ В немецкой политологии термин «Second-Order-Election» используется с 1980 г. Его основоположниками считаются К. Райф и Г. Шмидт. 
избирательного барьера для выборов в Европарламент усилила этот эффект и сделала возможным избрание в него партий регионального значения ${ }^{1}$.

15 марта 2019 г. Федеральный комитет ФРГ по выборам опубликовал решение, согласно которому к участию в выборах в Европарламент от Германии допускается 41 объединение: партии и общественные движения. Среди них 13 партий, в том числе парламентские: союз ХДС/ХСС (Христианский Демократический Союз и Христианский Социальный Союз (Бавария)), СДПГ (Социал-демократическая партия Германии), «Союз 90/Зелёные», «СвДП» (Свободная демократическая партия), «Левая», «Альтернатива для Германии»².

Это означает, что в Европарламент пройдёт много депутатов от малых партий. Количество мест в ЕП для стран распределяется неравномерно. Тем не менее, Германия получит наибольшее количество мест: из общего планируемого количества - 705-ти она может рассчитывать на 96 (на данный момент). Обычно партии в ЕП объединяются в 9 фракций:

1. «Европейская народная партия» (EVP): 215 мест, представлены немецкие партии ХДС и ХСС;

2. « Прогрессивный альянс социал-демократов» (S\&D): 189 мест, к ним примыкает СДПГ;

3. «Европейские консерваторы и реформисты» (ECR): на данный момент у них 73 места. К ним принадлежит Б. Луке представитель «Альфы» - партии, которая откололась от «Альтернативы для Германии». В новых избирательных списках ее нет;

2. Альянс либералов и демократов за Европу (Alde): 69 мест. К ним принадлежит немецкая СвДП;

3. Фракция объединённых европейских левых и северных зелёных левых (GUE/NGL): 52 места - немецкая партия «Левая»;

4. «Зелёные//Европейский Свободный Альянс» (EFA): 50 мест - немецкая партия «Союз 90/Зелёные;

5. «Европа свободы и прямой демократии» (EFDD): 44 места - «Альтернатива для Германии».

6. «Европа наций и свободы» (ENF): 39 мест, представительница «Голубых» Фрауке Петри - бывшая сопредседатель партии «АдГ». В этот раз баллотироваться не будет ${ }^{3}$.

С 2014 г. наиболее крупные европейские фракции во время избирательных кампаний представляют кандидаты из разных стран, задача которых персонализировать выборы в ЕП и тем самым привлечь к ним внимание граждан. Политикам регионального уровня от малых партий трудно задействовать ресурсы, необходимые для активизации граждан. Потому партии выбирают одного-двух наиболее известных политиков, которые ведут агитацию и участвуют в дебатах. Поскольку голосование в ЕП, в отличие от выборов в бундестаг, проходит по закрытым партийным спискам, избиратели, как правило, не знают лично депутатов, которые в итоге пройду в Европарламент, и голосуют за партии, исходя из своих общих электоральных предпочтений. Фактически результаты выборов в ЕП можно рассматривать как вотум доверия немецких граждан к национальным партиям - проверка их рейтинга и популярности у населения на данный момент.

\footnotetext{
${ }_{1}^{1}$ Избирательный барьер будет введён вновь в 2024 г.

2 Europawahl 2019: Der Bundeswahlausschuss lässt 41 Parteien und sonstige politische Vereinigungen zu. URL: https://www.bundeswahlleiter.de/info/presse/mitteilungen/europawahl-2019/08_19_1sitzung-bwa-zulassung.html.

${ }^{3}$ Там же.
} 


\section{Кандидаты в Европейский парламент от европейских фракций 2019 г.:}

- Христианские демократы (EVP): Манфред Вебер (Manfred Weber), Германия, XCC;

- Социал-демократы (SPE): Франс Тиммерманс, Нидерланды;

- Консерваторы (ECR): Ян Зарадил (Jan Zahradil), Чехия;

- Зелёные (EGP): Ска Келлер (Ska Keller), Германия и Бас Айкоут (Bas Eickhout), Нидерланды;

- Левые (EL): Нико Куе (Nico Cué), Бельгия и Виолета Тоимч (Violeta Tomič), Словения.

Дополнительно в Германии партии представляют местные политики: СДПГ - министр юстиции Катарина Барлей (Katarina Barley), СвДП - генеральный секретарь партии Никола Бeep (Nicola Beer) $\mathbf{1}^{\text {. }}$

В ФРГ, как правило, явка на европейские выборы невысока. В 2014 г. проголосовало около 48,1\% граждан. В 2019 г. согласно опросам общественного мнения, эта цифра не превысит 50\%. Тем не менее, наиболее активные избиратели используют выборы в ЕП для того, чтобы продемонстрировать традиционным партиям своёедовольство и преподнести им урок. Так получилось в 2014 г., когда право-популистская «Альтернатива для Германии» не сумела пройти в бундестаг, но показала хороший результат на выборах в Европарламент $(7,1 \%)$. Поэтому главный призыв правительственных партий в Германии в 2019 г. ХДС/ХСС и СДПГ «защитить европейский парламент и Европу от правых и левых популистов». В этот раз партии ХДС и ХСС впервые идут на евро-выборы с общей избирательной программой. В 2014 г. председатель ХCC X. Зеехофер построил избирательную стратегию партии на критике курса EC. Серьёзные разногласия между партнёрами по коалиции возникали и позже, наивысшего апогея спор между Х. Зеехофером и А. Меркель достиг в мае 2018 г. Камнем преткновения стала миграционная политика канцлерин и желание лидера ХСС вернуть ушедших к «АдГ» избирателей. Совместную предвыборную программу 2019 г. политики ХДС и ХСС преподносят немецкой общественности как примирение двух партий. Миграционный вопрос занял центральное положение в документе, основная цель которого создать чёткую систему контроля за прибывающими в Европейский союз беженцами по примеру Германии. ХДС/ХСС выступают за усиление охраны границ Евросоюза, создание специальных «Anker -центров» по регистрации, приёму и высылке иммигрантов, против регистрации права на убежище в нескольких странах одновре́менно. Впервые в избирательной программе содержится обещание не допускать ситуацию, при которой граждане других стран ЕС будут использовать социальную систему Германии для своей выгоды ${ }^{2}$. Все эти меры призваны не только реформировать миграционную систему Евросоюза в сторону её ужесточения, но и направлены на привлечение избирателей правого фланга, которые ушли к «АдГ».

Несмотря на усилия консервативного блока ХДС и ХСС немецкие правые из «Альтернативы для Германии» планируют набрать в этот раз 15\%. На сегодняшний день популярность партии находится на уровне $10 \%$. Некоторое падение в рейтинге накануне выборов можно объяснить проводимой в СМИ кампанией по дискредитации лидеров «АдГ» из-за «аферы с пожертвованиями» во время выборов в бундестаг.

\footnotetext{
1 Europawahl 2019 im Überblick: Termine, Kandidaten, Parteien. URl:https://www.merkur.de/politik/europawahl2019-termin-kandidaten-und-wichtigsten-fakten-zr-11750013.html.

2 Wahlprogramm der CDU/CSU für die Europawahl 2019. URL: https://www.merkur.de/politik/europawahl-2019wahlprogramme-von-cdu-csu-spd-freien-waehlern-und-anderen-parteien-zr-12003337.html.
}

Научно-аналитический вестник ИЕ РАН, 2019, №2 


\section{Место России в избирательных программах немецких партий}

Тема России в межпартийных дискуссиях накануне выборов в Европарламент практически не затрагивается. Тем не менее, вопрос о возможном вмешательстве Москвы в ход выборов периодически поднимается. Делают это, в том числе, ведущие политики. Например, кан-

\section{Прогноз итогов выборов в ЕП}

\begin{tabular}{|c|c|c|c|c|c|c|}
\hline ХДС/ХСС & СДПГ & $\begin{array}{l}\text { «Союз 90/ } \\
\text { Зел1ные» }\end{array}$ & $\begin{array}{c}\text { Альтернати- } \\
\text { ва для Гер- } \\
\text { мании }\end{array}$ & «Левая» & $\begin{array}{c}\text { СвДП } \\
\text { (либералы) }\end{array}$ & Другие \\
\hline $30 \%(2014$ г. 35,3\%) & $\begin{array}{l}17 \% \\
(2014 \Gamma . \\
27,3 \%)\end{array}$ & $\begin{array}{l}19 \% \\
(2014 \Gamma . \\
10,7 \%)\end{array}$ & $\begin{array}{l}11 \% \\
(2014 \Gamma . \\
7,1 \%)\end{array}$ & $\begin{array}{c}7 \% \\
(2014 \text { г. } \\
7,4\end{array}$ & $\begin{array}{c}7 \% \\
(2014 \Gamma . \\
3,4 \%)\end{array}$ & $9 \%$ \\
\hline
\end{tabular}

Источник: «Umfrage zur Europawahl 2019: Grüne vor Sensation, AfD vor Enttäuschung» URL:https://-www.derweste n.de politik/europawahl-2019-umfrage-in-deutschland-diese-partei-liegt-vorn-id216385951.html.

лерин А. Меркель обратила внимание общественности на такую возможность во время своего выступления на конференции по безопасности в Мюнхене. В целом немецкие СМИ считают, что Россия не оставила своих попыток повлиять на исход голосования, но делает это более осторожно, чем в период американской предвыборной кампании и голосования в Великобритании о её выходе из ЕС. На первом месте в программах партий и дискуссиях - воросы миграции и социальной справедливости.

В программах правительственных партий ХДС/ХСС, СвДП и «Союза 90/ Зелеые» нет положений, которые бы затрагивали отношения с Россией. Однако Россия упоминается наряду с США и Китаем в качестве вызова (соперника) для европейской безопасности, которую следует укреплять и усиливать путем созданиям европейской армии. Социал-демократы обещают предпринять все зависящие от них усилия для того, чтобы предотвратить гонку вооружений на европейском континенте и сохранить ДРСМД. Они надеются убедить США вернуться к этому договору, а Россию продолжить его соблюдать. СДПГ выступает за сохранение прежних договорных форматов и создание новых, к которым будут присоединяться другие страны. Они против размещения ракет средней и ближней дальности на территории Германии ${ }^{2}$ Для того чтобы ЕС говорил в вопросах внешней политики одним голосом и лидерам союза стало легче им управлять партии «большой коалиции» ХДС/ХСС и СДПГ предлагают отказаться от принципа единогласного принятия решений в совете министров Европейского союза и заменить его на «принцип большинства».

Исключение в вопросе отношения к России составляют две оппозиционные партии: «Альтернатива для Германии» и «Левая». Они выступают за отмену санкций и нормализацию отношений с РФ. При этом «левые» четко высказываются против участия Германии в НАТО, новой гонки вооружений, создания европейской армии и размещения ракет средней дальности на территории ФРГ ${ }^{2}$.

«АдГ» признаеёт за Германией необходимость вести более активную политику, направленную на защиту национальных интересов, а не идеологии. Потому ФРГ должна сознательно стать лидером ЕС. Партия выступает за «Европу отчеств (наций)», в которой националь-

\footnotetext{
${ }^{1}$ Kommt zusammen und macht Europa stark! Wahlprogramm der SPD für die Europawahl am 26. Mai 2019» URL: https://www.spd.de/fileadmin/Dokumente/Europa_ist_die_Antwort/SPD_Europaprogramm_2019.pdf

${ }^{2}$ Wahlprogramm der Partei DIE LINKE zur Europawahl 2019. Beschlossen auf dem Europaparteitag, Bonn, 22 . bis 23. Februar 2019. URL: https://www.die-linke.de/europawahl/wahlprogramm/
} 
ныle государства сами определят свою внешнюю политику. В вопросе европейской обороны «Альтернатива для Германии»делает ставку на франко-германский тандем. «АдГ» подчёркивает необходимость соблюдать международное право и особенно право наций на самоопределение и выступает против вмешательства во внутренние дела других государств или неправительственных организаций. Партия осознаёт историческое и экономическое значение России и призывает к обоюдному соблюдению интересов. Без России мир в Европе не мыслим. Между тем США остаются важным союзником Германии в сфере обеспечения безопасности. «АдГ» выступает за сотрудничество с Евразийским союзом и строительство газопровода «Северный поток 2», при котором будут учтены озабоченности восточноевропейских стран ${ }^{1}$.

\section{Расклад сил в Европейском парламенте}

Немецкие политологи уверенны, что расклад сил в Европарламенте 2019 г. будет отличаться от предыдущего 2014 г. Скорее всего европейским правым удастся выступить удачнее и завоевать в ЕП больше мест, что приведёт к утрате парламентского большинства двух ведущих европейских фракций: «Европейской народной партии» (EVP) и «Прогрессивного альянса социал-демократов» (S\&D). Для сохранения своего влияния они будут вынуждены пойти на кооперацию с другими малыми партиями, например либералами и зелёными. Заключать союз с правыми силами представители ведущих европейских партий на данном этапе отказываются. Тем не менее, самые высокие шансы, на наш взгляд, по-прежнему у «Европейской народной партии». Как самая крупная фракция она сможет провести своего кандидата на пост председателя Еврокомиссии. В случае успеха им станет представитель Германии Манфред Вебер (ХСС). Аналитики оценивают его шансы занять ключевой пост выше $60 \%$ (до 75\%). Новый председатель ХДС А. Крамп-Карренбаур поддержала кандидатуру М. Вебера - представителя баварской партии.

М. Вебер (46 лет, инженер по образованию) считается ярым критиком России. В отличие от нынешнего председателя Еврокомиссии Ж.-К. Юнкера он занимает чётко антироссийскую позицию. В отличие от своих коллег по партии (ХCC) М. Вебер публично выступает против строительства «Северного потока 2». Он пообещал притормозить проект, если станет председателем Еврокомиссии, т.к. рассматривает себя в качестве европейского, а не немецкого политика. М. Вебер высказывается официально против смягчения антироссийских санкций, за защиту интересов Украины. По его мнению, Россия не разделяет общие ценности с Европой ни в вопросе Украины, ни Сирии, распространяет «фейк-новости» и усиливает военную активность на восточной границе с Евросоюзом. Потому Европейский союз должен реагировать на российские действия решительно. Россия перестала, по его мнению, быть стратегическим партнёром, потому необходимо пересмотреть соглашение о партнёрстве между РФ и ЕС: «время красивого и дипломатического языка прошло»².

\section{Выводы}

Скорее всего EVP придётся кооперироваться с другими партнёрами-фракциями в ЕС для образования парламентского большинства и проведения своего кандидата на пост председателя Еврокомиссии, например, «зелёными» и/или «либералами». В любом случае, это не будут правые и левые партии, настроенные пророссийски. Следовательно, вероятность усиления антироссийского курса в новом ЕП очень высока. Представляется, что в некоторых вопросах

\footnotetext{
${ }^{1}$ Europawahlprogramm. Programm der Alternative für Deutschland für die Wahl zum 9. Europäischen Parlament 2019. URL: https://www.afd.de/wp-content/uploads/sites/111/2019/03/AfD_Europawahlprogramm_A5-hoch_web_150319.pdf. CDU - Hardliner Weber als Juncker-Nachfolger: Neue Konfrontationen mit Russland? URL: https://de.sputniknews.com/politik/20190321324409437-weber-juncker-russland-politik/
} 
М. Вебер может скорректировать свои предвыборные заявления, прежде всего, в отношении строительства газопровода «Северный поток 2», т.к. проект поддерживает правительство Германии, а предвыборные заявления кандидата от ХДС/ХСС направлены не только на привлечение немецкого избирателя, но и на завоевание голосов граждан восточноевропейских государств. В целом, мы наблюдаем смену поколений, когда всё более активную роль в ФРГ и Европе играют политики в возрасте 35-45 лет, ориентирующиеся на сотрудничество с США. У них нет за плечами опыта Второй мировой и холодной войны. Поэтому в ближайшие годы следует ожидать ужесточения подхода к выстраиванию диалога с Россией. Избирательные кампании предыдущих лет показали, что тема угрозы со стороны РФ используется для мобилизации собственных избирателей, которые уходят к правым партиям. США по-прежнему рассматриваются немецкими политическими партиями, включая «Альтернативу для Германии», как основной партнёр, с которым, несмотря на возникшие серьёзные сложности, следует продолжать сотрудничество, но на новом равноправном уровне. Для этого европейцы собираются усиливать собственную оборонную политику и продолжать строительство европейской армии, в центре которой будет франко-германское сотрудничество.

\section{Список литературы}

Швейцер В.Я. (2019) Обновление европейских властных структур: поиск идентичности. Научно-аналитический вестник ИЕ РАН, №1. С. 43-46.

Европа 2017: партии, выборы, власть. Отв. ред. В.Я. Швейцер. ДИЕ РАН №353. М., ИЕ PAH, 2018 г.

Трансформация партийно-политического ландшафта в странах Евросоюза в условиях кризиса. Часть 1. Отв. ред. Б.П. Гуселетов. ДИЕ РАН №337, М., ИЕ РАН, 2017 г.

Европейские выборы 2019: Шахматная игра в Центральной Европе.URL: https://www. geopolitica.ru/article/evropeyskie-vybory-2019-shahmatnaya-igra-v-centralnoy-evrope.

Выборы в Европарламент-2019. У кого больше шансов? URL: https://www.dw.com/cda/ru/

Как может измениться состав Европарламента в 2019 году. URL: https://news.rambler.ru/europe/41958989/?utm_content=rnews\&utm_medium=read_more\&utm_so urce $=$ copylink.

\section{References}

Europawahl 2019: Der Bundeswahlausschuss lässt 41 Parteien und sonstige politische Vereinigungen zu. URL: https://www.bundeswahlleiter.de/info/presse/mitteilungen/europawahl2019/08_19_1sitzung-bwa-zulassung.html.

Europawahl 2019 im Überblick: Termine, Kandidaten, Parteien. URl: https://www.merkur.de/ politik/europawahl-2019-termin-kandidaten-und-wichtigsten-fakten-zr-11750013.html.

Wahlprogramm der CDU/CSU für die Europawahl 2019. URL: https://www.merkur.de/politik/ europawahl-2019-wahlprogramme-von-cdu-csu-spd-freien-waehlern-und-anderen-parteien-zr12003337.html.

Kommt zusammen und macht Europa stark! Wahlprogramm der SPD für die Europawahl am 26. Mai 2019» URL: https://www.spd.de/fileadmin/Dokumente/Europa_ist_die_Antwort/SPD_Eu ropaprogramm_2019.pdf.

Wahlprogramm der Partei DIE LINKE zur Europawahl 2019, Beschlossen auf dem Europaparteitag, Bonn, 22. bis 23. Februar 2019. URL: https://www.die-linke.de/europawahl/wahlprogramm/

Europawahlprogramm. Programm der Alternative für Deutschland für die Wahl zum 9. Europäi- 
schen Parlament 2019. URL: https://www.afd.de/wp-content/uploads/sites/111/2019/03/AfD_Euro pawahlprogramm_A5-hoch_web_150319.pdf.

Europas Chancen nutzen - Das Programm der Freien Demokraten zur Europawahl 2019. URL: https://www.fdp.de/sites/default/files/uploads/2019/02/26/2019-01-27-bpt-europas-chancen-nutzendas-programm-der-freien-demokraten-zur-europawahl-2019.pdf.

Grünes Wahlprogramm zur Europawahl 2019. URL: https://www.gruene.de/artikel/grueneswahlprogramm-zur-europawahl-2019.

Umfrage zur Europawahl 2019: Grüne vor Sensation, AfD vor Enttäuschung. URL: https:// www.derwesten.de/politik/europawahl-2019-umfrage-in-deutschland-diese-partei-liegt-vorn-id2163 85951.html.

CDU - Hardliner Weber als Juncker-Nachfolger: Neue Konfrontationen mit Russland? URL: https://de.sputniknews.com/politik/20190321324409437-weber-juncker-russland-politik/

Forum Empirische Sozialforschung. Wählen, wählen, immer wieder wählen. Die Bundestagwahl und Europawahl im Vergleich. Viola Neu, Sabine Pokorny, 2014, Konrad-Adenauer-Stiftung. EV Sankt Augustin/Berlin. S. 31.

\section{Elections to the European Parliament May 26, 2019: Characteristics of the Election Campaign in Germany}

Author. Ekaterina Timoshenkova, Candidate of Sciences (History), Leading Research Associate, Deputy Head of the Center for German Studies of the Department of Country Studies, Institute of Europe, Russian Academy of Sciences. Address: 11-3, Mokhovaya str., Moscow, Russia, 125009. E-mail: katerinatim@mail.ru.

Abstract. The paper analyzes the preparation of German political parties for the elections to the European Parliament in 2019. The author identifies the main patterns of electoral behavior, studies the election programs and strategies of the parties represented in the Bundestag. This allows us to formulate a forecast of the election results in Germany and how they will affect the overall balance of power in the European Parliament. Particular attention is paid to the analysis of the positions of government and opposition parties in relation to Russia, as well as the prospects of German politicians for key positions in Brussels after the elections.

Key words: party-political system of Germany, government parties, opposition, European Parliament, euroscepticism, protest voting, electoral preferences, «Alternative for Germany», Russian-German relations.

DOI: http://dx.doi.org/10.15211/vestnikieran220195258 